\title{
A Research on the Relationships among Perceived Organizational Climate, Individual Creativity and Organizational Innovation
}

\author{
Gönül Kaya Özbăg \\ Kocaeli University \\ Y1ld1z Bilge Barbaros Shipping and Maritime School \\ Karamürsel/Kocaeli, Turkey \\ gonulozbag@gmail.com
}

\begin{abstract}
The main purpose of this study is to determine the influence of perceived organizational climate dimensions (organizational encouragement, supervisory support, peer support, autonomy, communication, participation flexibility) on individual creativity and organizational innovation which is a key driver for competitive advantage. The study is empirically based on the primary data collected from 86 medium and large sized organizations that are registered to Kocaeli Chamber of Industry. Data obtained from questionnaires will be analyzed through the SPSS statistical packet program and PLS-Graph. The results indicate that perceived organizational climate is positively related to individual creativity and organizational innovation.
\end{abstract}

Key Words: organizational climate, individual creativity, organizational innovation

\section{INTRODUCTION}

There isn't a consensus about the definition of climate in the literature. However, it can be described as collective attitudes, behaviors and feelings that continually produced and reproduced by the interactions of people and thus characterize life in the organization (Isaksen, Lauer, Ekvall \& Britz, Poole \& McPhee, 1983; Schneider, 1980). The reason for the lack of an agreed definition is appeared from two contradictory views; the cognitive schema approach and the shared perceptions approach. The prior assumes that organizational climate is to be regarded as an individual attribute and the latter as an organizational attribute when concerning the nature of climate; (Glick, 1985; James, Joyce, and Slocum,1988; Schneider and Reichers,1983). To make a reasonable distinction, James and Jones have suggested that "psychological climate" is more suitable for the prior and organizational climate for the latter. 
Schneider and Reichers (1983) suggest an other argument that work settings have different climates for specific things such as safety, service, production, security, and quality. They suggest that the chosen climate measure should be consistent with the intent of the research investigation since work settings have different climates for specific objectives. In that case, there may be consensus of perceptions among organizational members. Thus, we follow them and in this study we assess the climate by measuring individual employee perceptions of a number of factors shown to be correlated with creative behaviors. Because, of its modifying effect on organizational and psychological processes, organizational climate is seen as a significant variable that affects individual creative behaviour that in turn, affects organizational innovation.

As regards the climate measurement instruments, creative climate questionnaires (CCQs) developed by Ekvall (1996, 1997), The Team Climate Inventory (TCI) developed by Anderson and West (1996) and Amabile's KEYS: Assessing the Climate for Creativity (Amabile et al., 1996) is worth to examine. The TCI is based around four main factors: participative safety, support for innovation, vision, and task orientation (Anderson and West 1996). On the other hand, The CCQ instrument covers ten dimensions such as challenge, freedom, idea support, trust and openness, dynamism and liveliness, playfulness and humor, debates, conflicts, risk taking and idea time. Amabile's KEYS (1998) evaluate six dimensions of the work climate that affect creativity; encouragement of creativity (which encompasses fair, supportive evaluation of new ideas, collaborative information flow, encouragement of risk taking and idea generation, participative management and decion making); autonomy or freedom (the degree of individual ownership of and control over work); resources (time and money); pressures (positive challenge and negative work-load pressure); and organizational impediments to creativity (conservatism, internal strife rigid and formal management structures).

In summary, a variety of research arrives at some set of critical norms that may foster or impede innovation and creativity; supportive and challenging environment, commitment to ambitious, clearly specified, and attainable objectives or goals that are widely shared by the members of the organization, freedom and and risk taking, autonomy regarding the choice of tasks and how they are performed, encouragement of ideas, sufficient time for creating ideas, appropriate feedback and rewards, training, trust and openness, and leadership commitment and involvement (i.e. Amabile, Conti, Coon, Lazenby \& Herron, 1996; Oldham \& Cummings, 1996; Woodman et al., 1993; Abbey \& Dickson, 1983; Ekvall, 1996; Anderson \& West, 1999). We specify these findings as the basis for focusing our empirical investigation and organized the study as follows. First, the paper begins by discussing the theoretical background and research hypotheses of the main constructs (organizational climate, individual creativity and organizational innovation). Thereafter, it describes the research model, methods and results of the research. In conclusion, it discusses the implications of the study with regard to existing literature.

\section{ORGANIZATIONAL CLIMATE AND INDIVIDUAL CREATIVITY}

In the organization literature, many empirical studies have directly linked several organizational climate characteristics with desirable organizational outcomes such as creativity and innovation (Amabile, Conti, Coon, Lazenby, \& Herron, 1996; Abbey \& Dickson, 1983; Oldham \& Cummings, 1996; Scott \& Bruce, 1994: Woodman, Sawyer, 
\& Griffin 1993; Shalley, Gilson, \& Blum, 2000; Ekvall, 1996; West \& Anderson, 1996; Baer \& Frese, 2003). Some research findings confirm that innovative organizations achieve a climate conducive to innovative behaviours (Damanpour 1991; Amabile et al.,1996; Scott \& Bruce, 1994). Therefore, the concept of organizational climate in general, the relationship between organizational climate and creativity and innovation in particular, become popular subjects for academicians from a variety of research areas (e.g. Amabile et al., 1996, Scott \& Bruce, 1994, Oldham, Cummings, 1996; Damanpour 1991; Mohammad \& Rickards, 1996).

In a search to determine what makes a climate to be supportive of creativity and innovation, many studies have suggested a variety of different characteristics. One of these factors is organizational encouragement. Organizational encouragement is encouragement of creativity and innovation. It involves supporting new idea and setting an organizational reward system that recognizes creativity. Another characteristic of climate, among many others, is supervisory support. The relevant literature have pointed the important role of managers on employees' attitudes (Oldham and Cummings, 1996; Amabile, et al., 1996). The managers who encourage risk taking and idea generation and provide positive informational feedback, substantial freedom and autonomy, are positively related with creativity and innovation. Relatedly, Tesluk, Farr, and Klein (1997) identified five dimensions of organizational climate that influence creativity, including goal emphasis, means emphasis, reward orientation, task support, and socioemotional support.

Similarly, some researches indicated that organizational encouragement, supervisory support, autonomy and freedom, challenging job (Amabile et al., 1996) non-controlling and supportive supervisors (Cummings and Oldham, 1997), goal setting, rewards, and choice or personal discretion in work procedures can affect creativity. Some others have noted that innovative organizations are characterized by an orientation toward creativity and innovative change, support for their members in functioning independently in the pursuit of new ideas (Kanter, 1983; Siegel and Kaemmerer, 1978), and a tolerance for diversity among their members (Siegel and Kaemmerer, 1978). Furthermore, Dunegan et al. (1992) have found that divisional affiliation, work group interactions, and the quality of exchange between leader and subordinate significantly predict the perceptions of employees of climate factors believed to encourage innovative activities in the organization (Mohammad \& Rickards, 1996; 110).

In summary, a number studies have suggested that organizational climate has significant effect on the creative performance of individuals. Aspects such as task meaning and challenge, freedom and autonomy, team cooperation and friendliness, leadership support and organizational encouragement, sufficient resources have been brought forward as important features of organizational climate that fosters creativity (Abbey and Dickson, 1983; Scott \& Bruce, 1994; Amabile et al. 1996; Anderson \& West, 1996; Woodman, Sawyer, \& Griffin, 1993; Shalley, 1995; Cummings, Oldham, 1997). Drawing on early theory and research we describe the organizational climate that influence an employee's creativity consists of dimensions such as; organizational encouragement, supervisory support, peer support, autonomy, communication, participation flexibility. Thus, it's hypothesized that; 
H1: Organizational encouragement is positively related with individual creativity.

H2: Supervisory support is positively related with individual creativity.

H3: Peer support is positively related with individual creativity.

H4: Autonomy is positively related with individual creativity.

H5: Communication is positively related with individual creativity.

H6: Participation flexibility is positively related with individual creativity.

\section{INDIVIDUAL CREATIVITY AND ORGANIZATIONAL INNOVATION}

Creativity and innovation are closely related concepts but in essence, creativity is the generation of novel and useful ideas, primarily at the individual level whereas innovation can be described as the successful implementation of these creative ideas within an organization (Amabile et al., 1996). Creative work can be generated by employees in almost any job at any level of any organization (Shalley, Gilson, \& Blum, $2000 ; 215)$. "Thus, no innovation is possible without the creative processes that mark the front end of the process: identifying important problems and opportunities, gathering information, generating new ideas, and exploring the validity of those ideas" (Amabile, 2004, p. 1). In this view, creativity by individuals and teams is a starting point for innovation (Cumming \& Oldham, 1997: 23) and individual creativity is important in and of itself and can be conceptualized as a necessary first step or precondition required for innovation (Scott and Bruce, 1995; Shalley, Gilson, 2004).

Creativity at the individual level, through idea generation and implementation, is likely to lead to the development of innovative products at the organizational level (Gümüşlüoğlu, İlsev, 2009, 465). Shalley et al. (2004) state that creative employees' new ideas are transferable to other employees in the organization for their own use and development. Creative individuals can mobilize the motivation needed to meet innovative demands. Morover, they are likely to spend more time on creative cognitive processes to develop problem solutions that are qualitatively high as well as the generation of ideas or solutions, and they make serious efforts to seek sponsorship for ideas and produce prototypes. Therefore, they can perform specific tasks successfully and achieve organizational innovation goals in the face of obstacles (Hsu, Hou\& Fan, 2011, p.260-261).

To sum up, there seems to be a great agreement among scholars of creativity and innovation that all innovation begins with creative ideas and the creativity of the people is a key source of organizational innovation. Since foundation of organizational creativity and innovation is ideas, and it is people who "develop, carry, react to, and modify ideas" (Van de Ven, 1986: 592), we expect idividual creativity will be positively related to organizational innovation, and suggest the following hypothesis.

H7:Individual creativity is positively related with organizational innovation. 


\section{METHODOLOGY}

\section{A. Research Design}

The proposed conceptual model guiding this research is depicted in Fig. 1. Organizational climate is hypothesized consisting of six dimensions such as organizational encouragement, supervisory support, peer support, autonomy, communication, participation flexibility have significant positive effect on individual creativity. Morover, it is predicted that individual creativity has significant positive effect on organizational innovation.

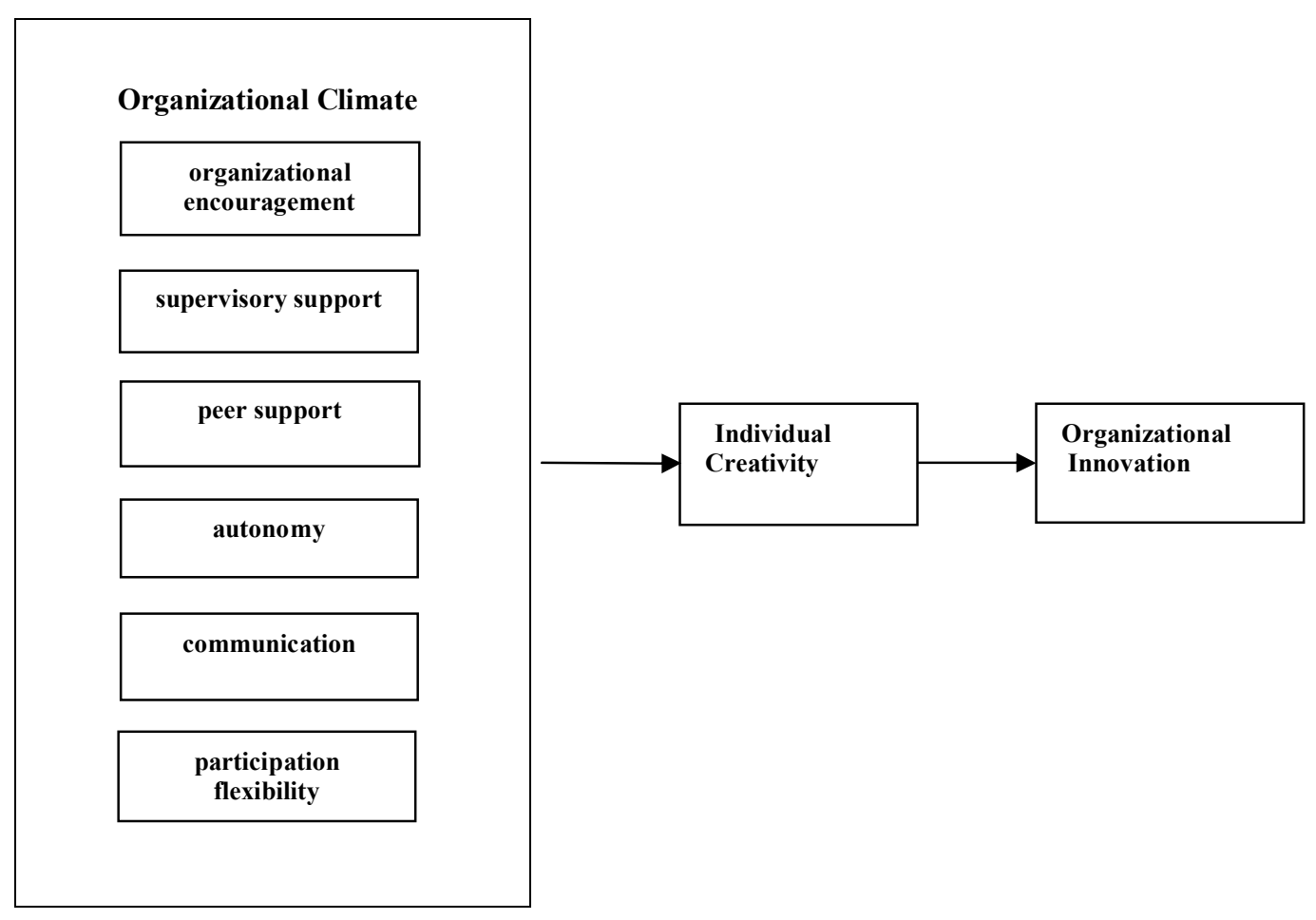

Figure 1. Proposed Model

\section{B. Scales and Sampling}

The purpose of this paper is to describe and analyze the mutual relationships among organizational climate, individual creativity, and organizational innovation. In order to empirically investigate the hypotheses, firms operating in Kocaeli were surveyed. Using the documents of Kocaeli Chamber of Commerce, 250 firms among 518 are identified as the target group of the research because of their availableness. Tools such as e-mail, letter and face to face interviews are used for gathering data from the managers. A total of 138 questionnaires among 86 firms has returned. Of the participants, $\% 62$ are married, $\% 53$ have university educations and $\% 8$ have master education.

To test the above hypotheses, multi-item scales adopted from prior studies for the measurement of constructs were used. Organizational climate was measured by 28 items developed from the studies of Amabile, Conti, Coon, Lazenby, Heron (1996), Scott and Bruce (1994) and Oldham and Cummings (1996). Individual creativity was measured by 10 items adopted from the creative behaviour measure of George and Zhou (2001). Organizational innovation was measured by 10 -items developed from the studies of Hansen and Birkinshaw (2007) and Hult et al. (2004). All items were rated 
using a 5-point scale ranging from 1 ("Very strongly disagree") to 5 ("Very strongly agree").

\section{Analysis and results}

Partial Least Squares (PLS) approach to path modeling is used to estimate the measurement and structural parameters in structural equation model (SEM) (Chin, 1998). The reason for using this technique is that PLS method can operate under limited number of observations and more discrete or continious variables. PLS is also a latent variable modeling technique that incorporates multiple dependent constructs and explicitly recognizes measurement error (Karimi, 2009). In addition, PLS is far less restrictive in its distributional assumption and it applies to situations where knowledge about the distribution of the latent variables is limited and requires the estimates to be more closely tied to the data compared to covariance structure analysis (Fornell and Cha, 1994). . Another benefit of PLS over other SEM techniques such as AMOS and LISREL is that it allows both formularize and reflective indicators to be used in the model (Fornell and Bookstein, 1982). Therefore, this study used PLS in Visual PLS software.

\section{Measurement validation}

Following the proposal of Straub (1989), the survey instrument was re-examined in terms of reliability and construct validity although the scale questions were developed from items successfully used in previous surveys. First of all, the original survey which consists of 30 questions was analyzed by PLS-Graph program and 2 item is found below the suggested loading value 0.70 and communal value. 50 (Fornell and Larcker), as suggested in literature these "below threshold" items are deleted (Hair, Tatham, Anderson and Black, 1998). Examination of the remaining items revealed that they adequately represent the underlying construct attesting to the content validity of the instrument. Tablo 1. indicates reliability scores of remained items.

Table 1. The standart loading, composite reliability and AVE values of the items

\begin{tabular}{|c|c|c|c|c|c|c|c|}
\hline $\begin{array}{l}\text { Org.Enc. } \\
\text { CR: } 0,83 \\
\text { AVE: } 0,65\end{array}$ & $\begin{array}{l}\text { Sup.sup. } \\
\text { CR:0,88 } \\
\text { AVE:0,75 }\end{array}$ & $\begin{array}{l}\text { Peer sup. } \\
\text { CR: } 0,93 \\
\text { AVE: } 0,53\end{array}$ & $\begin{array}{l}\text { Autonomy } \\
\text { CR:0,91 } \\
\text { AVE: } 0,60\end{array}$ & $\begin{array}{l}\text { Comm. } \\
\text { CR:0,835 } \\
\text { AVE:0,65 }\end{array}$ & $\begin{array}{l}\text { Part.flex. } \\
\text { CR:0,82 } \\
\text { AVE: } 0,59\end{array}$ & $\begin{array}{l}\text { Indiv.Crea. } \\
\text { CR: } 0,89 \\
\text { AVE: } 0,70\end{array}$ & $\begin{array}{l}\text { Org.Inno. } \\
\text { CR: } 0,92 \\
\text { AVE: } 0,59\end{array}$ \\
\hline $\begin{array}{l}.843 \\
.805 \\
.788 \\
.760 \\
.715 \\
.612\end{array}$ & $\begin{array}{l}.823 \\
.795 \\
.786 \\
.603 \\
.591 \\
.547\end{array}$ & $\begin{array}{l}.866 \\
.723 \\
.704 \\
.602\end{array}$ & $\begin{array}{l}.751 \\
.709 \\
.686 \\
.597\end{array}$ & $\begin{array}{l}.798 \\
.763 \\
.748 \\
.615\end{array}$ & $\begin{array}{l}.846 \\
.703 \\
.609 \\
.573\end{array}$ & $\begin{array}{l}.778 \\
.765 \\
.745 \\
.744 \\
.732 \\
.605 \\
.600 \\
.582 \\
.582 \\
.549\end{array}$ & $\begin{array}{l}.796 \\
.781 \\
.718 \\
.669 \\
.637 \\
.604 \\
.603 \\
.591 \\
.560 \\
.528\end{array}$ \\
\hline
\end{tabular}

\section{Hypothesis testing}

According to the correlation results seen in Tablo 2, there is a positive significant result among all dimensions of organizational climate and individual creativity and also between individual creativity and organizational innovation. 
G. Kaya Özbağ 6/1 (2014) 21-31

Table 2. Correlations of latent variables

\begin{tabular}{|l|c|c|c|c|c|c|c|c|}
\hline Variables & 1 & 2 & 3 & 4 & 5 & 6 & 7 & 8 \\
\hline Org.enco. & 1 & $.185^{*}$ & $.225^{* *}$ & $.238^{* *}$ & $.242^{*}$ & $.239^{* *}$ & $.263^{* *}$ & $.230^{* *}$ \\
\hline Sup.sup. & & 1 & $.424^{* *}$ & $.327^{* *}$ & $.328^{*}$ & $.181^{*}$ & $.255^{*}$ & $.275^{*}$ \\
\hline Peer sup. & & & 1 & $.330^{* *}$ & $.315^{* *}$ & $.223^{* *}$ & $.258^{* *}$ & $.328^{* *}$ \\
\hline Auto. & & & & 1 & $.196^{* *}$ & $.127^{* *}$ & $.354^{* *}$ & $.454^{* *}$ \\
\hline Comm. & & & & & 1 & $.284^{* *}$ & $.217^{*}$ & $.209^{*}$ \\
\hline Part. Flex. & & & & & & 1 & $.215^{*}$ & $.223^{* *}$ \\
\hline Indiv.Creat & & & & & & & 1 & $.415^{* *}$ \\
\hline Innov. & & & & & & & & 1 \\
\hline
\end{tabular}

PLS path modeling which allows for explicit estimation of latent variable (LV) scores is used to estimate the main effects in the proposed model (see Figure 1). PLS Graph 3.0 and Bootstrapping resampling method is used to test their statistical significance. This procedure entailed generating 500 sub-samples of cases randomly selected, with replacement, from the original data. Path coefficients were then generated for each randomly selected subsample. T-statistics were calculated for all coefficients, based on their stability across the subsamples, indicating which links were statistically significant.

Table 2. Hypothesis Testing Results

\begin{tabular}{|c|l|c|c|}
\hline Hypothesis & \multicolumn{1}{|c|}{ Relationship } & $\begin{array}{c}\text { Path } \\
\text { coefficient } \\
(\boldsymbol{\beta})\end{array}$ & Results \\
\hline H1 & Org.enc. $\rightarrow$ Individual Creativity & $.22^{* *}$ & Supported \\
\hline H2 & Sup. Sup. $\rightarrow$ Individual Creativity & $.28^{* *}$ & Not Supported \\
\hline H3 & Peer sup. $\rightarrow$ Individual Creativity & -.02 & Supported \\
\hline H4 & Autonomy $\rightarrow$ Individual Creativity & $.37^{* *}$ & Supported \\
\hline H5 & Communication $\rightarrow$ Individual Creativity & $.27^{* *}$ & Supported \\
\hline H6 & Part. flex. $\rightarrow$ Individual Creativity & $.41^{* *}$ & Supported \\
\hline H7 & Individual Creativity $\rightarrow$ Innovation & $.36^{* *}$ & Supported \\
\hline
\end{tabular}

As shown in Table 2, the results illustrate that suggested hypotheses are largely confirmed. With regard to effects of dimensions of organizational climate on individual creativity, it is found that organizational encouragement $(\beta=.22, \mathrm{p}<.01)$, supervisory support $(\beta=.28, \mathrm{p}<.01)$, co-worker support $(\beta=.27, \mathrm{p}<.01)$, autonomy $(\beta=.37, \mathrm{p}<$ 
$.01)$, open communication channels $(\beta=.27, \mathrm{p}<.01)$, participation flexibility $(\beta=.41$, $\mathrm{p}<.01)$ are positively related to creative behavior. Therefore $\mathrm{H} 1, \mathrm{H} 2, \mathrm{H} 4, \mathrm{H} 5, \mathrm{H} 6$ is supported but $\mathrm{H} 3$ is not supported. Further, it is found that individual creativity is positively associated with innovation $(\beta=.36, \mathrm{p}<.01)$, supporting $\mathrm{H} 7$.

\section{CONCLUSION AND IMPLICATIONS}

This study examine organizational climate as an indicator of the capacity of organizations to become innovative. Consistent with the previous research, the results of the study indicate that organizational climate positively affects individual creativity that are serving as raw material for later organizational innovations ( Shalley et al. 2004, p.952 ). This result implies that if the individuals perceived that their organization support innovative actions, they perform increased ability to develop new ideas and different solutions to problems. It also suggests that creative thinking is something that must be vigorously cultivated by the organization. Therefore, it can be stated that a climate that encourages a higher sense of creativity would probably generate more innovative products, services and processes.

Organizational practices, policies and systems can enhance creative and innovative behaviours of individuals by influencing individual's behaviour and attitude. If firms wish to increase their level of innovation they should recognise the value of their employees as generators of creative ideas. A climate that discourages employee risk-taking is always a serious barrier to innovation because people are often demotivated by the fear of failure. For that reason, managers must recognise the challenge of developing and implementing the correct context for individuals to feel motivated and committed to the creation of new products and processes.

On the other hand, peer support is negatively related to individual creativity in our case but we can clearly declare that peer support within an organization is likely to reduce conflict and enhance unity, communication and harmony within the rest of the organization, all of which have been found to be associated directly with creative and innovative outcomes (e.g., Sethi et.al, 2001). Maybe, the other dimensions of organizational climate have a strong effect on individual creativity that tends to override the positive effect of peer support in this study.

To conclude, this study provides important findings and guiding related to innovation management practices for Turkish companies and managers and as well as other developing countries since Turkey can be considered quite safely as representative of many developing countries. In addition, Turkish culture has long been described as being high on collectivism and power distance which is defined as "The extent to which the less powerful persons in a society accept inequality in power and consider it as normal" (Hofstede, 1980). For that reason, although numerous studies have explored the phenomenon of organizational climate, Turkish collectivistic culture with high-power distances may be different from those that influence empowerment in individualistic Western cultures with low-power distances.

In addition, although Turkey is regarded as a developing country much like South Korea, Brazil and Mexico, based on the World Economic Forum rankings, it ranks 56th in innovation among 80 nations. For that reason businesses in Turkey have begun to pay special attention to innovation in recent years in order to compete in the global arena. Therefore, the results of this research would increase awareness of Turkish managers in innovation process. Further, it is hoped innovation performance of Turkish firms would 
improve as depicted in the study by the positive link between organizational climate, individual creativity and organizational innovation. Consequently, the results of this study would provide some useful findings to both the literature and practitioners.

Despite this study offers a number of contributions to the literature, like all researches it has some limitations. First of all, organizational climate is a very large and comprehensive issue that concerns the whole of the organization and for that reason it can not be investigated in one research with its every dimensions. This study focuses some specific dimensions that is likely to boost individual creativity but future researchers would examine the role of other dimensions of organizational climate identified in organization theory such as work pressure, job design, empowerment and leadership. It can also be suggested to other researchers who wants to study in this subject to investigate the effect of organizational climate dimensions on other desirable outcomes such as commitment and satisfaction.

\section{REFERENCES}

Abbey, A., ft Dickson. J. W. (1983), "R\&D work climate and innovation in semiconductors", Academy of Management Joural, say1: 26, s. 362-368.

Amabile, T.M., Conti R., Coon H., Lazenby J. and Herron M. (1996), “Assessing The Work Environment For Creativity", Academey Of Management Journal, say1: 39(5), ss. 1154-1184.

Amabile, T. M. (1988), "A Model of Creativity and Innovation in Organizations, In B. M. Staw \& L. L. Cummings (Eds.)”, Research in Organizational Behavior, say1: 10 , ss. 123-167.

Amabile Teresa M., Schatzel Elizabeth A., Moneta Giovanni B. and Kramer Steven J. (2004), "Leader Behaviors and the Work Environment for Creativity: Perceived Leader Support", Administrative Science Quarterly, sayı: 15(1), ss. 5-32.

Anderson, N. R. and West, M. A. (1996), "The Team Climate Inventory: The development of the TCI and its applications in teambuilding for innovativeness", European Journal of Work and Organizational Psychology,sayı: 5, ss. 53-66.

Baer Markus and Frese Michael (2003)," Innovation is not enough: climates for initiative and psychological safety, process innovations, and firm performance", Journal of Organizational Behavior, sayı: 24, ss. 45-68

Chin W. (1998), "Issues And Opinion On Structural Equation Modeling." Mis Quarterly, sayı: 22(1), ss. 7-6.

Cummings, A. and Oldham, G. R. (1997), "Enhancing Creativity: Managing Work Contexts For The High Potential Employee", California Management Review, say1: 40 , ss. $22-38$.

Damanpour, F. (1991), "Organizational Innovation: A Meta Analysis Of Effects Of Determinants And Moderators", Academy Of Management Journal, say1: 34(3), ss. 555-590. 
Dunegan, K.J., Duchon, D. \& Uhl-Bien, M. (1992), "Examining the link between leader member exchange and subordinate performance: The role of task analyzability and variety as moderators", Journal of Management, vol.18, no.1, ss. 59-76.

Ekvall, G. (1996), “Organizational climate for creativity and innovation”, European Journal of Work and Organizational Psychology, sayı: 5 (1), ss.105-123.

Ekvall, G. (1997), “Organizational Conditions and Levels of Creativity”, Creativity and Innovation Management, say1: 6, ss.195-205.

Fornell C, Cha J. (1994), "Partial Least Squares", Advanced Methods Of Marketing Research, say1: 407, ss. 52-78.

Fornell, C., \& Larcker, D. F. (1981), "Evaluating structural equation models with unobservable variables and measurement error", Journal of Marketing Research, sayı: 18, ss.39-50.

Fornell C and Bookstein F L (1982), "Two Structural Equation Models: LISREL and

PLS Applied to Consumer Exit-Voice Theory", Journal of Marketing Research,

Vol. 19, No. 4, pp. 440-452.

George, J. M., \& Zhou, J. (2001), "When openness to experience and conscientiousness are related to creative behavior: An interactional approach", Journal of Applied Psychology, sayı: 86(3), ss.513-524.

Glick, W. H. (1985)," Conceptualizing and Measuring Organizational and Psychological Climate: Pitfalls in Multilevel Research", Academy of Management Review, Vol. 10, No.3, ss.601-616.

Gumusluoglu Lale and Ilsev Arzu (2009), "Transformational Leadership, Creativity, And Organizational Innovation", Journal Of Business Research, say1: 62(4), ss.461-473.

Hair, J. E., Anderson, R. E., Tatham, R. L., \& Black W. C. (1998), “Multivariate data analysis. (5th ed.)", Upper Saddle River, NJ: Prentice-Hall.

Hansen T. Morten ve Birkinshaw Julian, (Haziran 2007), "The Innovation Value Chain", Harvard Business Review.

Hult G.M.T., Hurley R.F. and Knight G. A., (2004), "Innovativeness: Its Ancedents And Impact On Business Performance", Industrial Marketing Management, sayı: 33, ss. 429-438.

Hsu Michael, L. A., Hou Sheng-Tsung and Fan Hsueh-Liang (2011), "Creative SelfEfficacy And Innovative Behavior In A Service Setting: Optimism As A Moderator", Journal Of Creative Behavior, sayı: 45(4), ss.258-272.

Isaksen Scott G., Lauer Kenneth J., Ekvall Göran and Britz Alexander (2000-2001), "Perceptions of the Best and Worst Climates for Creativity: Preliminary Validation Evidence for the Situational Outlook Questionnaire", Creativity Research Journal, Vol. 13, No. 2, ss.171-184.

Kanter, R. M. (1983), “The Change Masters”, New York: Simon \& Schuster.

Kanter, R., M. (1982), "Dilemmas Of Managing Participation”, Organizational Dynamics, say1: 11, ss.5-29. 
Karimi J. (2009), "Emotional Labor And Psychological Distress: Testing The Mediatory Role Of Work-Family Conflict", European Journal Of Social Sciences, say1: 11(4), ss.584-598.

Mohamed, M.Z. \& Rickards,T. (1996), Assessing And Comparing The İnnovativeness And Creative Climate Of Firms", Scandinavian Journal of Management, sayı: 12(2), ss.109- 121.

Oldham, G., Cummings, A. (1996), " Employee Creativity: Personal And Contextual Factors At Work," Academy Of Management Journal, sayı: 39(3), ss. 607-634.

Scott, S. and Bruce, R. (1994), “Determinants Of Innovatıve Behavior: A Path Model Of Individual Innovaton In The Workplace,” Academy Of Management Journal, say1: 37(3), ss.580-607.

Schneider, B. (1980), "The service organization: climate is crucial", Organizational Dynamics, say1: 9, ss.52-65.

Abbey, A. and Dickson, J. W. (1983)," R\&D Work Climate And Innovation In Semiconductors", Academy Of Management Journal, sayı: 26, ss.362-368.

Schneider, B. (1983), "Work climates: An interactionist perspective. In N. W. Feimer \& E. S. Geller (Eds.), Environmental psychology: Directions and perspectives", New York: Praeger, ss. 106-128.

Sethi, Rajesh, Smith, D.C. and Park, C.W. (2001), "Cross-Functional Product Development Teams, Creativity, and the Innovativeness of New Consumer Products", Journal of Marketing Research, say1: 38(1), ss.73-85.

Shalley, C., Gilson, L. and Blum, T. (2000), "Matching Creativity Requurrements And The Work Environment: Effects On Satisfaction And Intentions To Leave", Academy Of Management Journal, sayı: 43(2), ss. 215-223.

Shalley, C., Zhou, J. and Oldham, G. (2004), "The Effects Of Personal And Contextual Characteristics On Creativity: Where Should We Go From Here", Journal Of Management, say1: 30(6), ss.933-958.

Siegel, S., \& Kaemmerer, W. (1978), "Measuring the perceived support for innovation in organizations", Journal of Applied Psychology, say1:63, ss.553-562.

Straub, Detmar W. (1989), "Validating Instruments in MIS Research,” MIS Quarterly, say1: 13 , ss.147-169.

Tesluk, P. E., Farr, J.L,\& Klein, S. A. (1997), "Influences of organizational culture and climate on individual creativity", Journal of Creative Behavior, sayı: 31(1), ss.27-41.

Van De Ven, A. (1986), "Central Problems In The Management Of Innovation", Management Science, sayı: 32, ss.590-607.

Woodman, R., W., Sawyer, J.,E. And Griffin, R., W. (1993), "Toward A Theory Of Organizational Creativity", Academy Of Management Review, sayı: 18(2), ss.293-317. 